\title{
Trade-offs between mitigation costs and temperature change
}

\author{
Geoffrey Blanford • James Merrick • Richard Richels • \\ Steven Rose
}

Received: 20 November 2012 / Accepted: 10 August 2013 / Published online: 7 September 2013

(C) The Author(s) 2013. This article is published with open access at Springerlink.com

\begin{abstract}
This paper uses the MERGE integrated assessment model to identify the leastcost mitigation strategy for achieving a range of climate policies. Mitigation is measured in terms of GDP foregone. This is not a benefit-cost analysis. No attempt is made to calculate the reduction in damages brought about by a particular policy. Assumptions are varied regarding the availability of energy-producing and energy-using technologies. We find pathways with substantial reductions in temperature change, with the cost of reductions varying significantly, depending on policy and technology assumptions. The set of scenarios elucidates the potential energy system transformation demands that could be placed on society. We find that policy that allows for "overshoot" of a radiative forcing target during the century results in lower costs, but also a higher temperature at the end of the century. We explore the implications of the costs and availability of key mitigation technologies, including carbon capture and storage (CCS), bioenergy, and their combination, known as BECS, as well as nuclear and energy efficiency. The role of "negative emissions" via BECS in particular is examined. Finally, we demonstrate the implications of nationally adopted emissions timetables based on articulated goals as a counterpoint to a global stabilization approach.
\end{abstract}

\section{Introduction}

This paper attempts to provide insights into the economic costs, and actual climate implications, of limiting global warming - an issue that is the subject of considerable debate both within the analytical and the policy communities. Our analysis employs the MERGE model,

This article is part of the Special Issue on "The EMF27 Study on Global Technology and Climate Policy Strategies" edited by John Weyant, Elmar Kriegler, Geoffrey Blanford, Volker Krey, Jae Edmonds, Keywan Riahi, Richard Richels, and Massimo Tavoni.

This paper was prepared for the Energy Modeling Forum-27 Study. The views expressed here are solely those of the individual authors and do not necessarily represent those of the Electric Power Research Institute (EPRI) or its members.

Electronic supplementary material The online version of this article (doi:10.1007/s10584-013-0869-2) contains supplementary material, which is available to authorized users.

G. Blanford $\cdot$ J. Merrick $\cdot$ R. Richels $(\bowtie) \cdot S$. Rose

Electric Power Research Institute, Palo Alto, CA, USA

e-mail: rrichels@epri.com 
a $\boldsymbol{m}$ odel for $\boldsymbol{e x p l o r i n g} \boldsymbol{r}$ egional and $\boldsymbol{g l o b a l} \boldsymbol{e}$ ffects of energy policy. MERGE is an Integrated Assessment Model (IAM) that provides a reduced-form description of the economy, the energy sector, emissions, concentrations, radiative forcing and average temperature change. For a range of assumptions, with MERGE we are able to identify the least-cost mix of technologies for meeting a climate objective.

Like virtually all models being actively used in the climate debate, MERGE is continually being adapted to assess the implications of new policy proposals. Among the most noteworthy enhancements to the current version is the inclusion of BECS, bio-energy with carbon dioxide capture and geologic storage. By storing $\mathrm{CO} 2$ from the combustion of biomass feedstocks, this technology could result in "negative" $\mathrm{CO} 2$ emissions into the atmosphere. When used in sufficient quantities it could substantially offset the warming attributed to fossil fuel use. However, there are as of yet unresolved questions related to the availability of biomass and CCS that must be resolved before we can truly know the full potential of BECS. A brief description of MERGE and its numerical assumptions can be found in appendix 1 .

Ours is a cost-effectiveness, not a benefit-cost analysis. We examine the impacts of meeting various stabilization targets in terms of GDP foregone-where GDP losses are measured solely in terms of the "dead-weight" losses associated with reducing emissions. We do not attempt to calculate the reduction in damages brought about by a particular policy. To the extent we consider benefits; it is in terms of the reduction in temperature change associated with reducing emissions. ${ }^{1}$

We begin by describing the scenarios and their underlying assumptions. They are designed to address the following questions: What would happen, if because of risk aversion or technical challenges, nuclear power is tightly constrained and/or CCS is unavailable? How might substantial improvements in energy efficiency affect the costs of meeting a target? What are the benefits of breakthroughs in the costs and availability of biomass? For extremely tight targets, what are the benefits and costs of allowing overshoot? And finally, what would be the benefits of capturing the $\mathrm{CO} 2$ from biomass and storing it beneath ground?

\section{Scenarios design}

\subsection{Policy design}

A series of scenarios has been designed to explore how the attributes of various technologies affect the costs and effectiveness of policies in meeting their goal. We examine four policy scenarios. Two are top-down in their design, that is, a constraint is applied to total radiative forcing and two are bottom-up, where constraints are placed on the emissions of individual groups of countries.

\subsection{Top-down policies}

In the case of the tightest policy, $2.8 \mathrm{os} \mathrm{W} / \mathrm{m}^{2}$, radiative forcing must be $2.8 \mathrm{~W} / \mathrm{m}^{2}$ in 2100 , but overshoot ("os") of this radiative forcing level is allowed during the intervening decades. A higher 2100 target of $3.7 \mathrm{~W} / \mathrm{m}^{2}$ is also evaluated. However, in this case the upper limit is enforced in all time periods, that is, overshoot prior to 2100 is not allowed. Thus, the two topdown policies differ both in terms of their 2100 target and whether overshoot is allowed. Allowing overshoot in the 2.8 os policy is very important as a $2.8 \mathrm{~W} / \mathrm{m}^{2}$ policy without overshoot

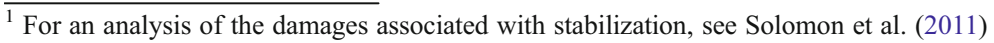


is a significantly more stringent policy with substantial cost, and even infeasibility, implications (see, for instance, Clarke et al. 2009). The $2.8 \mathrm{os} \mathrm{W} / \mathrm{m}^{2}$ target is approximately equivalent to a 450 ppmv CO2-eq limit on atmospheric concentrations. The $3.7 \mathrm{~W} / \mathrm{m}^{2}$ policy regime corresponds to limiting atmospheric concentrations to $550 \mathrm{CO} 2$-eq, or approximately twice preindustrial levels. Significantly, these two policies assume that all countries collaborate from the outset (in 2020) and thus there is complete "when" and "where" flexibility in mitigation options. We note that these are extremely optimistic; indeed many would say unrealistic assumptions. We explore "bottom-up" approaches to climate policy in the next section..

\subsection{Bottom-up policies}

In the bottom-up scenarios, emissions constraints are placed on individual groups of countries. ${ }^{2}$ We begin by describing what we refer to as the G8m policy. ${ }^{3}$ This scenario is intended to represent a significant break from current trends in favor of more aggressive action. Here, Group 1 (primarily the wealthier countries that comprise the greater OECD) and Group 2 (their less economically developed counterparts) aim at a $50 \%$ reduction of their combined emissions (CO2-eq) relative to 1990 by 2050. Group 1 agrees to strive for an $80 \%$ reduction and Group 2, adopts an emission cap necessary to achieve the goal of $50 \%$ reduction in combined Group 1 and 2 emissions. Emissions trading is permitted between Group 1 countries prior to 2020, and between Groups 1 and 2 countries from 2020 on. After 2050, reductions of $2 \%$ per year of emissions from Group 1 and 2 countries are adopted for the remainder of the century. Group 3 (the fossil fuel resource owners in the Middle East and Russia) are assumed to have little incentive to participate in the coalition and remain unconstrained during the 21 st century.

We compare this to an alternative future called the Fragmented Policy (FP). Whereas the G8m scenario is based on aggressive, coordinated action, the FP scenario is designed to reflect heterogeneous national commitments of stringency more consistent with practical expectations about ability and willingness to pay. In this case, Group 1 adopts a cap of $50 \%$ emissions reductions (CO2-eq) relative to 2005 in 2050. Emissions trading is permitted between Group 1 countries prior to 2020, After 2020, net emissions permit exports from Group II to Group I are limited to $20 \%$ of the Group 1 mitigation requirement (i.e. the difference between baseline emissions and emissions allowances under the cap). After 2050, emissions are reduced by $2 \%$ per year. Group 2 adopts emission constraints through 2020 corresponding to their Copenhagen pledges. After 2020, Group 2 countries make emissions reductions relative to their baseline based on their income. Once a Group 2 country reaches a specified income level, its emissions allowance is reduced by $2 \%$ per year. As with the former policy, Group 3 emissions are unconstrained throughout the $21^{\text {st }}$ century.

\subsection{Technology assumptions}

The availability and attributes of several technologies are also varied in the analysis. We focus on the impact of alternative assumptions about the rate of energy efficiency (EE) improvements (as measured in the model by the autonomous energy efficiency improvements, or AEEI,

\footnotetext{
2 These scenarios are described in Blanford et al. submitted for this volume.

${ }^{3}$ We use the label G8m to indicate that the scenario in this analysis, while consistent with the original motivation of the proposal put forward by the Group of Eight Countries, has been modified for the current exercise. Specifically, we exclude fossil fuel resource owning countriesin the Middle East and Russia from the mitigation coalition. These countries are referred to as the Group 3 countries.
} 
parameter), the future of nuclear and CCS generation, and the availability of sustainable biomass. In each case we construct a more optimistic ("high") and a more pessimistic ("low") variant, although we eschew judgment as to which is more realistic (see Table 1). These variants are combined into several scenarios in order to identify key sensitivities.

Table 1 summarizes the technology scenarios. The most optimistic scenario is referred to as the Full Portfolio, and the most pessimistic as the Limited Portfolio. The other scenarios explore mixed alternatives. The table includes a column noting scenario numbers that correspond to particular technology configurations used in the overall EMF-27 Study (multiple scenario numbers refer to alternative policy cases).

Our approach, following and extending the structure of the EMF27 exercise, is to examine each of the policy scenarios separately against each of the technology scenarios. However, in the case of the $2.8 \mathrm{os} \mathrm{W} / \mathrm{m}^{2}$ policy scenario, certain technology variants turn out to be critical for computing feasibility, so that in the more limited technology cases, the target cannot be met within the model's standard parameterization. Specifically, for those cases where CCS is not available, the 2100 target is relaxed to $2.84 \mathrm{~W} / \mathrm{m}^{2}$, although we continue to refer to it as a $2.8 \mathrm{os} \mathrm{W} / \mathrm{m}^{2}$ target in all cases (with overshoot).

\section{Results by policy scenario}

\subsection{2 .8 os target}

We move next to an exploration of the $2.8 \mathrm{os} \mathrm{W} / \mathrm{m}^{2}$ target. The three panels constituting the left side of Fig. 1 show emissions, radiative forcing, and temperature change, respectively for a range of technology scenarios. These include the Default case, a case with low bioenergy potential ("Low Bioenergy"), and a case without CCS availability ("Low CCS"). As represented in Table 1, Low Bioenergy and Low CCS are independent sensitivity scenarios, i.e., the latter

Table 1 Technology scenario design

\begin{tabular}{llllll}
\hline & EE & CCS & Nuclear & Bioenergy & EMF27 \\
\hline Full portfolio & High $^{\mathrm{a}}$ & High $^{\mathrm{c}}$ & High $^{\mathrm{e}}$ & High $^{\mathrm{g}}$ & G2,10,18 \\
Low bioenergy & Low $^{\mathrm{b}}$ & High & High & Low $^{\mathrm{h}}$ & G5,14,22 \\
Low CCS & Low & Low $^{\mathrm{d}}$ & High & High & G1,11,19 \\
Low nuclear & Low & High & Low $^{\mathrm{f}}$ & High & G3,12,20 \\
Low CCS/nuclear & Low & Low & Low & High & G7,16,24 \\
Limited portfolio & Low & Low & Low & Low & G8,30,25 \\
Default & Low & High & High & High & G1,9,17 \\
\hline
\end{tabular}

\footnotetext{
${ }^{\mathrm{a}}$ AEEI rate is multiplied by 1.6

${ }^{\mathrm{b}}$ Reference AEEI rates

${ }^{\mathrm{c}}$ Standard CCS technologies are available

${ }^{\mathrm{d}} \mathrm{CCS}$ technologies are not available

${ }^{\mathrm{e}}$ New nuclear generation is able to expand

${ }^{\mathrm{f}}$ No new nuclear generation is deployed globally beyond plants currently under construction

${ }^{g}$ Constrained only by regional resource limits

${ }^{\mathrm{h}}$ Constrained to $100 \mathrm{EJ}$ per year of global primary energy

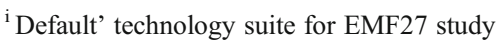


is simply Low CCS, not Low Bioenergy and Low CCS. In the Default case, the model is able to make full use of the BECS technology in the electric sector (subject to our assumed resource limits on sustainable biomass production) to create net negative carbon emissions by the end of the century. In the Low Bioenergy case, the use of BECS is partially constrained due to the lower availability of biomass, and in the Low CCS case it is completely constrained due to the unavailability of CCS. Note the $3.7 \mathrm{~W} / \mathrm{m}^{2}$ results in Fig. 1 are discussed in the next section.

As shown in Fig. 1(a), the emissions pathway for meeting the $21002.80 \mathrm{os} / \mathrm{m}^{2}$ target is highly dependent on the ability to deploy BECS. In the Default case, the optimal pathway is only moderately stringent in the near term because of the tremendous opportunity for future abatement with BECS. The greater the opportunity to deploy BECS, the greater is the amount of overshoot, i.e., higher near-term emissions and lower end-of-century emissions. If CCS is never available, there is no opportunity for BECS and the target can only be met by drastic and immediate cuts. It is the Low CCS technology variant that proved infeasible under the standard configuration with a $2.80 \mathrm{~s} \mathrm{~W} / \mathrm{m}^{2}$ target, which raises questions about the viability of even more stringent targets and targets for which overshoot is not permitted.

Figure 1(b) shows the implications for radiative forcing. The rise in emissions in the nearterm in the Default case leads to a continued increase in forcing; the negative emissions "scrubbing" of atmospheric CO2 leads to a rapid decline later on. On the other hand, if CCS is not available, there can be very little overshoot without other options for negative emissions. The implications for actual (transient) temperature change, which is a lagged function of total radiative forcing, are shown in Fig. 1(c). The chart indicates that the assumptions about biomass supply and CCS can have a profound effect on the temperature pathway. Perhaps ironically, the scenario with the most pessimistic technology assumptions leads to the lowest temperature pathway. The conventional result would be that more technology options facilitate more aggressive cost-effective mitigation. Removing the option of overshoot via BECS decreases temperature by as much as $0.4^{\circ} \mathrm{C}$ in 2100 . This result suggests that great care be taken when interpreting results from overshoot policy scenarios, since the (uncontrolled) extent of overshoot has a first-order impact on the ultimate effectiveness of the policy, in terms of both the level and rate of temperature rise.

Figure 2 shows the deployment of technology in the electric and nonelectric sectors under the three technology scenarios described above for the $2.80 \mathrm{~s} \mathrm{~W} / \mathrm{m}^{2}$ policy. In the electric sector, note the small role of conventional fossil fuels with CCS relative to that of BECS. With a very tight target, the primary value of CCS is in enabling negative emissions via BECS. We can observe that when CCS is available, most biomass is directed to electric generation with BECS -the direct air capture services are more valuable than using biomass in the non-electric sector. ${ }^{4}$

Without the prospect of future negative emissions, as in the Low CCS case, the tight target requires large and rapid contraction of fossil fuel based energy. As shown later, this reduction in energy supply is tremendously costly for the economy.

Nuclear and renewable generation play large roles in addition to BECS, especially when there is no CCS. In the non-electric sector, which must eventually become carbon-free as well, there is tremendous reliance on the backstop in the latter years, e.g., hydrogen via photovoltaics and electrolysis. We note that this is but one example of a non electric backstop. In the spirit of Nordhaus (1979), "the costs of new unproven technologies must perforce be laden with uncertainty." We have attempted to place an upper bound on the cost of carbon-free nonelectric energy that is available in unlimited quantities at constant marginal

\footnotetext{
${ }^{4}$ Applications of CCS in the non-electric sector, which could also lead to negative emissions when combined with a biomass feedstock, are certainly possible but not included in the current version of MERGE.
} 


\section{$\underline{2.80 \mathrm{SW} / \mathrm{m}^{2}}$}

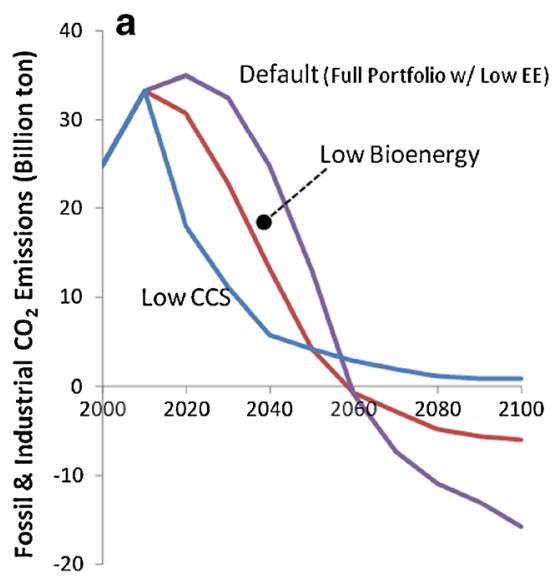

\section{$\underline{3.7 \mathrm{~W} / \mathrm{m}^{2}}$}

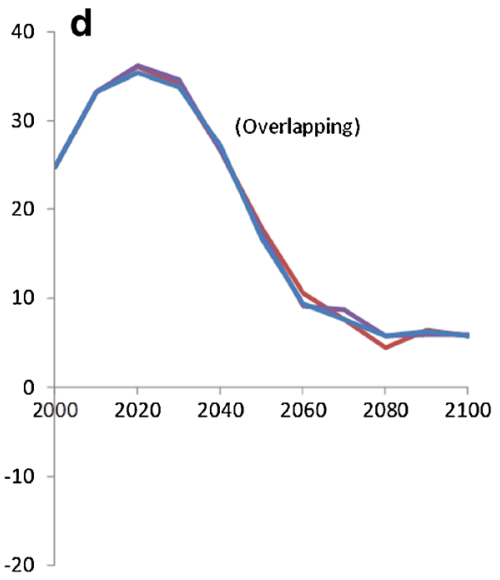

EE)

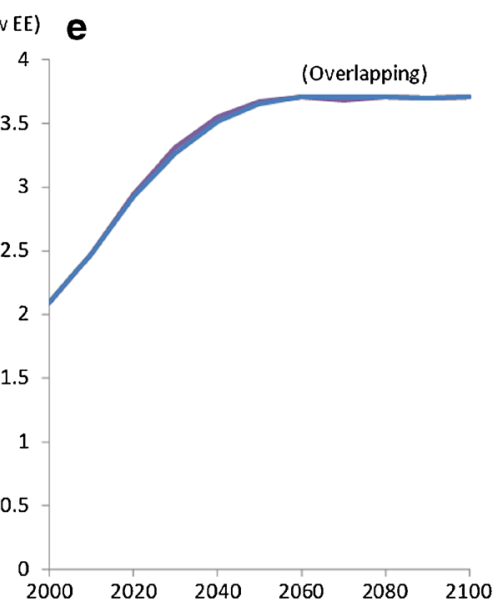

3 f

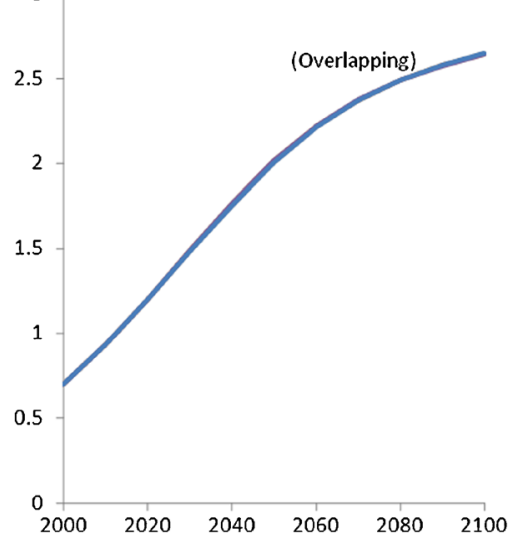

Fig. 1 Emissions, radiative forcing and temperature change for the 2.8 os (left hand side) and 3.7 (right hand side) $\mathrm{W} / \mathrm{m}^{2}$ targets 

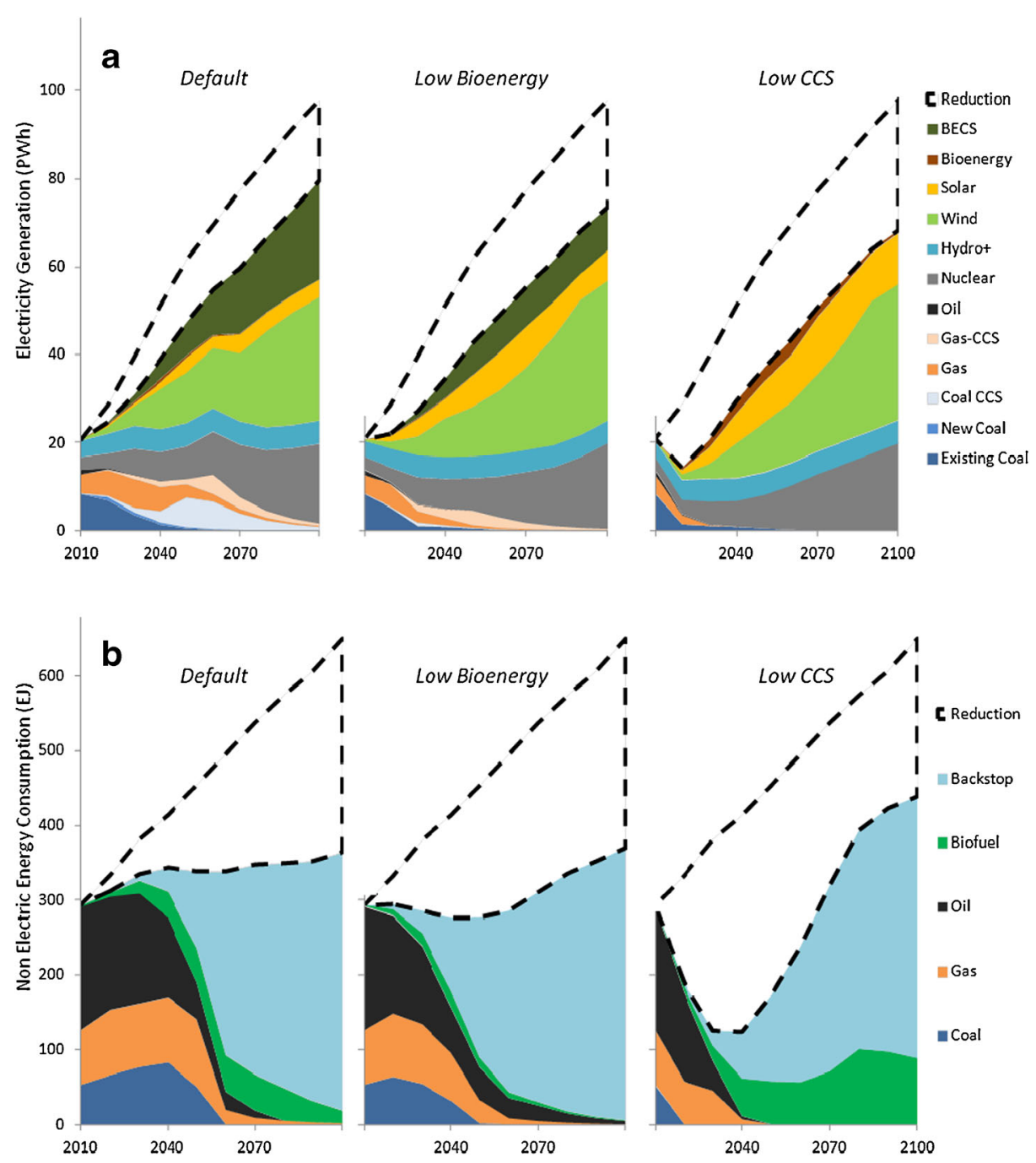

Fig. 2 Global electric generation by technology (a) and non-electric energy use by fuel (b) in $2.80 \mathrm{os} / \mathrm{m}^{2}$ scenario

cost. There are a number of technologies drawing upon superabundant resources that might fit this description. Hence our example is only meant to be illustrative.

\section{$3.23 .7 \mathrm{~W} / \mathrm{m}^{2}$ target}

So what if a less stringent target is pursued, without overshoot? The right side of Fig. 1 shows emissions (d), radiative forcing (e) and temperature change (f), respectively for the same range of technology scenarios discussed for the $2.8 \mathrm{os} \mathrm{W} / \mathrm{m}^{2}$ target.

Whereas the more stringent target had a wide range of emissions, forcing, and temperature outcomes, varying with the availability of BECS, the $3.7 \mathrm{~W} / \mathrm{m}^{2}$ "not-to-exceed" pathway is largely insensitive to technology. Also, the target is not sufficiently stringent to necessitate a 
negative emissions flow. However, the requirement that forcing never exceed the target level allows less "when" flexibility relative to the case when overshoot is allowed, since it effectively places a limit on "indebtedness" during the transition.

Note that roughly the same amount of $\mathrm{CO} 2$ is released into the atmosphere in each scenario. This result reflects the role of BECS in creating "headroom" for continued fossil fuel use. This is particularly true for the nonelectric sector, where there are fewer and more expensive substitutes for coal, gas, and oil applications (not shown). Without BECS (i..e in the Low CCS case), 2100 non-electric emissions fall $90 \%$ in the $3.7 \mathrm{~W} / \mathrm{m}^{2}$ case relative to BAU (versus $66 \%$ when BECS is available to the electric sector in the Default case).

\subsection{Bottom-up policy scenarios}

Thus far our focus has been on the top-down policies to stabilize radiative forcing. All countries are assumed to participate from the outset with full "when" and "where" flexibility. This is likely an optimistic assumption. We now turn to a "second best" world, one where participation may be staggered and some countries do not choose to participate (at least during the present century). These bottom-up policies are intended to represent scenarios which are more tangible and realistic about commitments that individual countries might adopt.

Figure 3 shows emissions and reductions from baseline in 2100 for the G8m and FP scenarios with country groupings disaggregated. In both policy regimes, Group 1 emissions are nearly eliminated, and in fact are slightly negative in the Full Portfolio when BECS is available. The major difference between the two policies is in the level of mitigation occurring in Group 2 countries (such as China, India, and most other currently developing nations). In the G8m scenario, the goal imposed on the combined emissions of Groups 1 and 2 implies that drastic reductions happen in both groups. Group 2 also has net negative emissions by the end of the century. Meanwhile, the target formula in FP for countries with relatively lower incomes leads to still significant but smaller reductions. It is important to note that the chart shows $\mathrm{CO} 2$ emissions only, while the emissions limits are defined in terms of a sum of all Kyoto gas emissions on a CO2-equivalent basis. However, because the

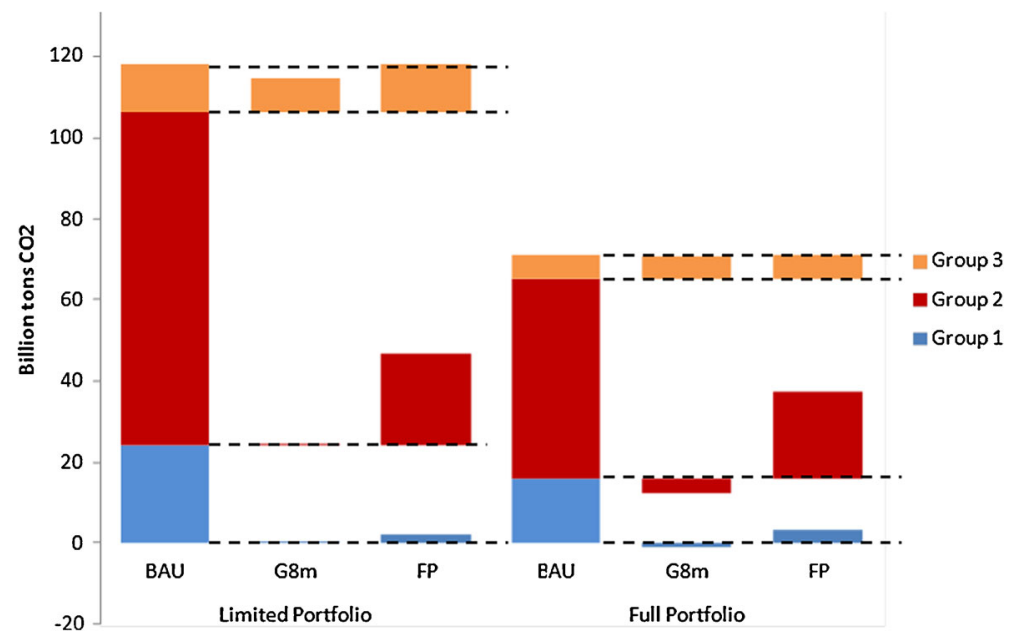

Fig. $32100 \mathrm{CO} 2$ emissions by country grouping in BAU, G8m, and FP policy scenarios 
MERGE model has only limited reduction potential in most non-energy sectors, reductions in the energy sector must compensate. ${ }^{5}$ Finally, Group 3 emissions track BAU closely, and as mentioned above are much lower in the Full Portfolio due to energy efficiency. Group 3 is a relatively small component of global emissions in the baseline, but a large fraction of the remaining emissions in the policy cases, especially in G8m. Although many raise concerns about emissions leakage to non-participants through trade and other effects, MERGE in fact displays "negative" leakage in that Group 3 emissions in the G8m scenario are lower than BAU. This is because the reduction in conventional oil demand in Groups 1 and 2 obviates the transition to more carbon-intensive liquid substitutes in the baseline, thus emissions in Group 3 are lower despite actually consuming more energy (positive leakage through the fuel price). In effect, oil-exporters get to consume more of their own product while the rest of the world decarbonizes.

Figure 4 compares the global emissions pathways across all policy regimes in the Full and Limited Portfolio scenarios. The impact of the accelerated energy efficiency improvements assumed in the Full Portfolio indicates that much larger percentage-based cuts are required with standard efficiency assumptions. The G8m scenario as implemented is roughly consistent with a $3.7 \mathrm{~W} / \mathrm{m}^{2}$ stabilization regime (rather than the more stringent target $2.8 \mathrm{os}$ $\mathrm{W} / \mathrm{m}^{2}$ case), while the FP case results in stabilization of emissions, rather than concentrations or forcing. From an historical perspective, all policy scenarios except the FP require a radical departure from the past. The current growth trajectory in non-OECD countries (Groups 2 and 3), which encompass $80 \%$ of the world's population but only just over half its emissions, implies that affordable carbon-free technologies must be available and rapidly deployed in these emerging and industrializing economies if we hope to meet any of the more stringent targets considered here.

\section{Comparing temperature change and GDP losses across policies}

The results described in the previous section present a range of pathways to alternative climate outcomes. Ultimately, the analysis seeks to illustrate the cost implications of these alternatives and how effectively they contribute to climate mitigation. Costs in our analysis are measured in terms of deadweight loss, that is, GDP foregone in order to achieve a mitigation goal. Figure 5 gives some insight into the importance of the technology assumptions in the cost of each policy. The figure shows cumulative GDP losses discounted to 2010 at $5 \%$ per year.

Most notable is the exceptionally high costs for the $2.80 \mathrm{os} / \mathrm{m}^{2}$ target when CCS, and thus BECS, is not available. In these constrained cases, there is enormous pressure to transform the energy system immediately. When CCS and BECS are available, the target pathway can take advantage of "negative" emissions in the second half of the century, closer to the target date, and the near-term cuts need not be so deep and costly.

Interestingly, constraining nuclear has a lesser impact on GDP losses than the absence of CCS. When nuclear is available it plays a substantial role, particularly in the low energy efficiency case. But when it is unavailable, other "zero" emitting technologies are available to replace it (typically at a cost). But there is no replacement (in our model) for the negative emissions flow enabled by BECS when CCS is unavailable.

The $3.7 \mathrm{~W} / \mathrm{m}^{2}$ target is somewhat more relaxed. Again, BECS plays an important role in reducing GDP losses. Recall that BECS plays two potentially important and overlapping

\footnotetext{
${ }^{5}$ This dynamic is discussed in more detail in Blanford et al. (2009).
} 

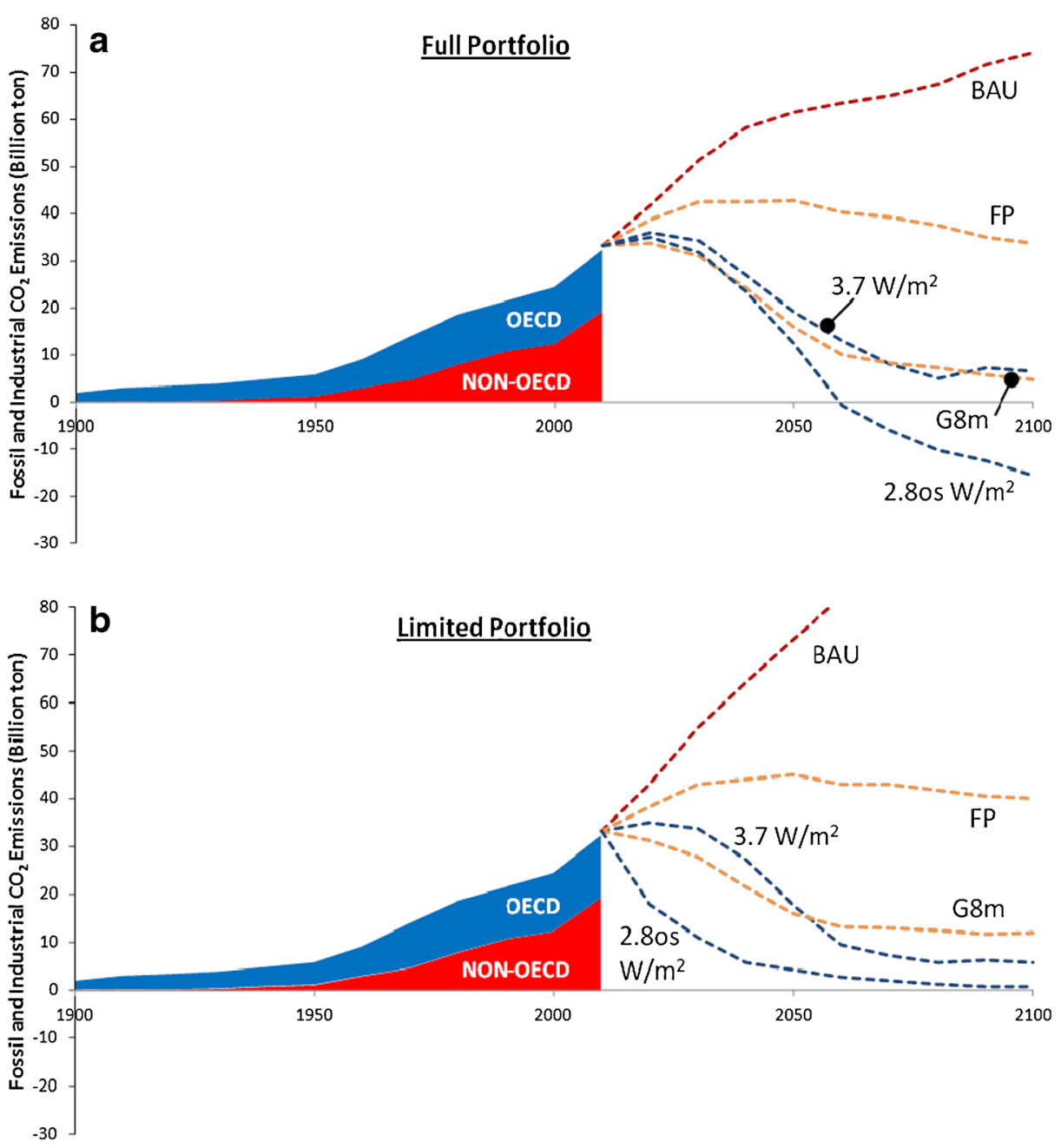

Fig. 4 Historical CO2 emissions and emissions pathways for policy cases under both Full Portfolio (a) and Limited Portfolio (b) technology cases

roles. However, its role is restricted to creating "headroom" for fossil fuels that otherwise would have to be replaced or reduced.

Next, we turn to the two bottom-up policies, both of which exclude the Group 3 countries. Compared to the globally harmonized regime implied by the top-down policies, this incomplete participation presents a major obstacle to economic efficiency since the entire burden falls on Group 1 and Group 2 countries. The G8m policy is particularly difficult. All countries in Groups 1 and 2 must participate from the outset to meet an ambitious constraint. Since trade in emission rights with Group 3 is prohibited, these countries are forced even higher up their marginal abatement cost curves to meet their goals. Compounding the difficulty is that the stipulated target for 2050 must be met in that year, constraining "when" flexibility in addition to "where" flexibility. Interestingly, although the G8m radiative forcing path is quite similar to that of the 


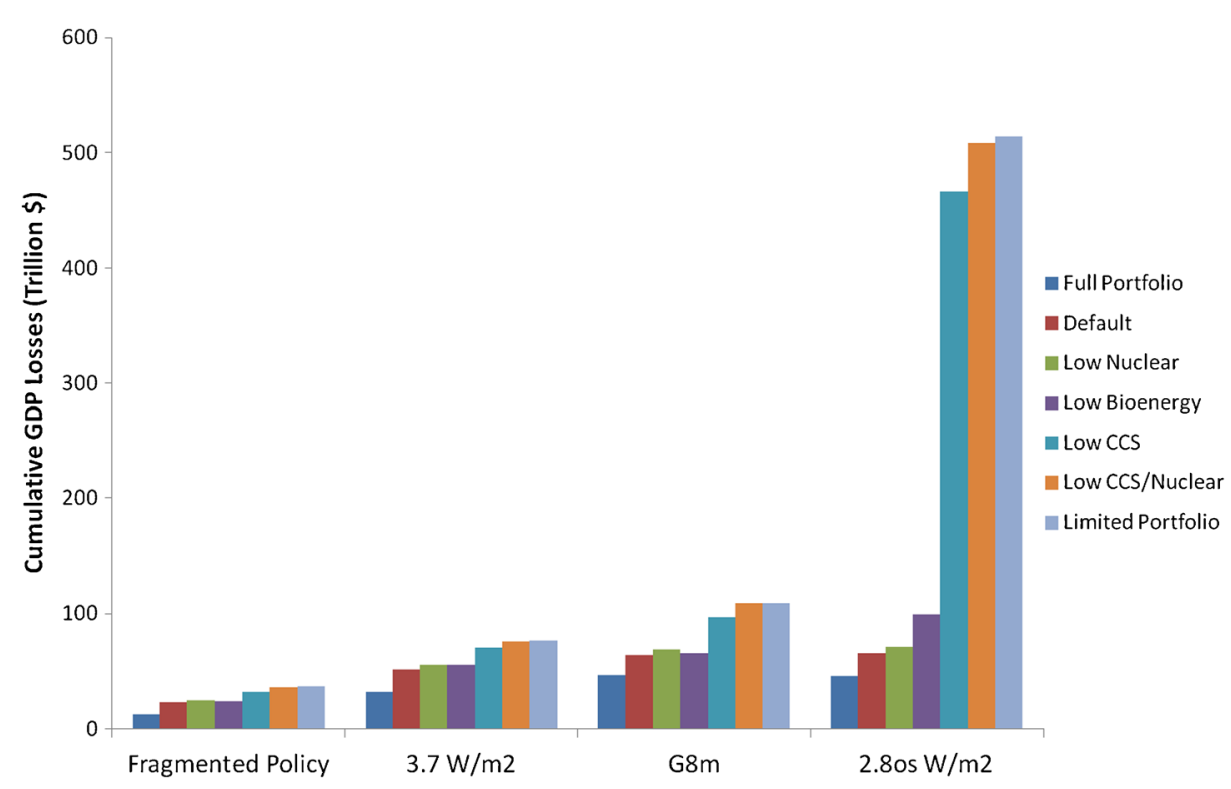

Fig. 5 Present value of 2010-2100 cumulative GDP loss across policy and technology cases

3.7 W/m $\mathrm{m}^{2}$ target, the costs are much higher, showing the impact of economic inefficiency. The FP constraint is less ambitious, both in terms of the level and schedule of reductions.

Figure 6 provides projections of temperature increase to the end of the century (relative to preindustrial levels), annotated with the GDP loss associated with each pathway with the Full and Limited Portfolios. The length of the arrows to the right of the chart indicates reduction in temperature rise in 2100, while their width and label font size reflect the cumulative GDP loss pictured in Fig. 5. This juxtaposition is intended to provide insights into the costs and climate benefits of selecting a particular policy with different technology at one's disposal. We stress, however, that we do not suggest how much a particular temperature reduction may be worth. With this said, we offer the following observations.

While the $2.80 \mathrm{~s} \mathrm{~W} / \mathrm{m}^{2}$ policy leads to the lowest temperature outcome by 2100 , only in the Limited Portfolio case is it significantly lower than the other two stringent policies $\left(3.7 \mathrm{~W} / \mathrm{m}^{2}\right.$ and G8m). As highlighted above, the option for overshoot in the Full Portfolio weakens the ultimate effectiveness if measured by impact on temperature.

When the $2.80 \mathrm{~s} \mathrm{~W} / \mathrm{m}^{2}$ case does separate from the pack in terms of temperature, via rapid immediate reductions rather than long-term negative emissions, it does so at significant relative expense. The scale of this expense is determined by how rapidly new technologies can deploy to replace the retired emitting technologies, and meet the demand for valuable energy use. The analysis, while not explicitly designed to answer this question, suggests that in the neighborhood of $2^{\circ}$ above pre-industrial, the marginal cost of an additional unit of avoided temperature change is extremely high under standard rate of transition assumptions.

We also note the similarity in the paths between $\mathrm{G} 8 \mathrm{~m}$ and $3.7 \mathrm{~W} / \mathrm{m}^{2}$ policies. They are very close in terms of temperature change, but the globally harmonized and flexible structure of the $3.7 \mathrm{w} / \mathrm{m}^{2}$ policy creates a distinct savings in terms of GDP losses. 

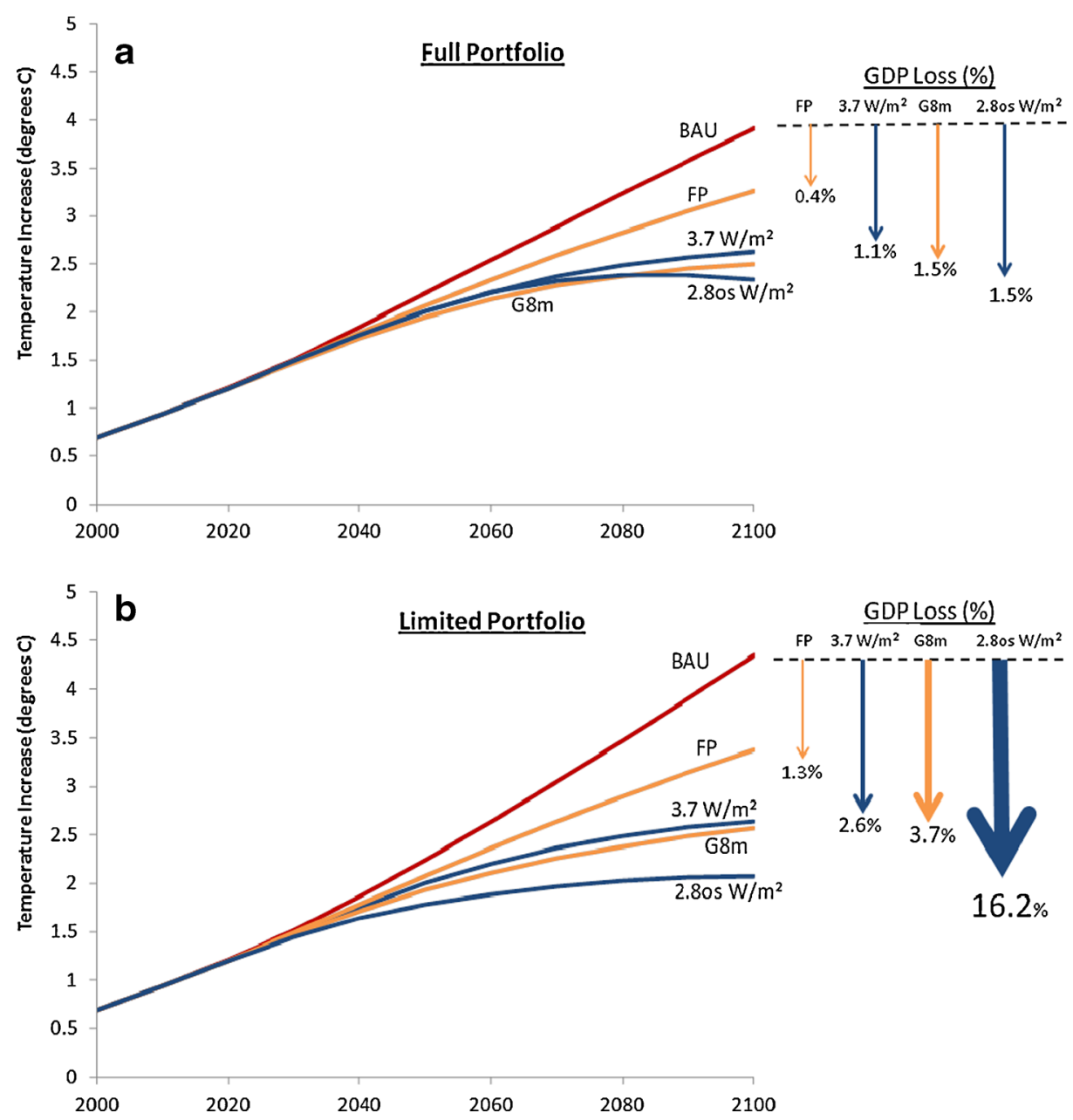

Fig. 6 Temperature change vs. cumulative GDP loss across policy scenarios (orange represents bottom-up policies, and blue represents top-down policies) in the full portfolio (a) and limited portfolio (b) technology cases

\section{A closer look at the $2.80 \mathrm{~S} \mathrm{~W} / \mathrm{m}^{2}$ target}

Our analysis assumes a number of pieces fall into place in the $2.80 \mathrm{~s} \mathrm{~W} / \mathrm{m}^{2}$ policy. In one scenario, the combination of CCS and large-scale sustainable bioenergy production is available to future generations, allowing net negative emissions later on, and the near-term mitigation pathway is aggressive but not extreme. On the other end of the spectrum, the option for negative emissions in the future is unavailable, and the present generation engages in immediate drastic emissions reductions. Both pathways rely on large wind and nuclear growth, and the later pathway also employs significant solar combined with a global weaning off of fossil fuels by mid-century. Clearly, both pathways involve grappling with demanding societal transformations fraught with challenging issues and uncertainty.

Along the first pathway, we rely heavily on the emergence of a particular technology. While CCS has been demonstrated, and biomass boilers for electric generation exist today, and there is no fundamental technology barrier involved in combining them, nonetheless it is 
far from clear that BECS can be deployed at the scale seen in this analysis. With respect to biomass supply, there are social concerns related to induced land-use change, potential food price effects, and net environmental concerns that could constrain biomass feedstock use. ${ }^{6}$ There are also engineering issues with large scale energy conversion of biomass feedstocks, such as handling and fouling; and BECS facilities have yet to be demonstrated. ${ }^{7}$ With respect to CCS, capture is costly but proven, geologic storage potential is vast, yet the prospects for effectively storing $\mathrm{CO} 2$ underground, perhaps forever, remain unknown. $\mathrm{CO} 2$ is heavier than air, and a major leak during the transportation or sequestration stage could lead to substantial loss of life. We do not suggest that CCS or BECS should not or could not play a substantial role in the transition to climate stabilization, but more analysis of the risks and benefits is needed to make an informed decision. At the present time, we have incomplete information on both sides of the ledger.

The second pathway instead commits us to reducing emissions as fast as possible. This forces an examination of how quickly new low- or zero-carbon energy supply technologies could in fact be brought online. There would likely be limits based on bottlenecks in financial or commodity markets, which are difficult to quantify. Political will for such a transition is certainly another ingredient. For example, if there emerged an unequivocal perception of impending and calamitous climate change, might we not be induced to remove barriers wherever possible to the adoption of new technologies? It is possible that such an environment is more consistent with the sense of urgency that would go along with the adoption of a policy like the $2.8 \mathrm{os} \mathrm{W} / \mathrm{m}^{2}$ target. We acknowledge that the circumstances leading to the adoption of such a policy may currently be unlikely. We also note that our measurement of mitigation costs is limited to the deadweight losses associated with adopting one set of technologies over another to achieve a climate target. As such it does not account for other costs that may be incurred by accelerating the turnover of the energy capital stock: the social costs (e.g. related to unemployment or displacement), the costs of accelerating R\&D, or the political "capital" spent to engineer the transition. Implementation of aggressive climate targets needs to be examined in terms of both social, as well as economic costs, and to the extent possible, benefits.

In either pathway, we have also assumed universal participation in the coalition from the outset. Will all countries be willing to take substantial action beginning in 2020? If past experience is an indication, the prospects are bleak. We do not rule out such an eventuality, but considerable and compelling evidence will be needed of the possibility of impending and significant consequences without substantial emissions reductions.

Finally, it must be emphasized that from an environmental perspective, an overshoot is problematic. To the extent exercised, an overshoot could involve rapid increases in radiative forcing in the near-term and thus more rapid rise in temperature. However, the consequences of global warming may be due as much to the rate of temperature change as absolute temperature. Moreover, the higher temperature and rates of change associated with overshoot may bring us closer to "tipping points" at which irreversible or discontinuous changes occur. That is, it is unclear whether we can return to the same planet we left. ${ }^{8}$ Overshoot enhances our ability to shift effort away from the present, when mitigation costs are highest, toward the more distant future when we will (presumably) have greater technological wherewithal to make emission reductions (perhaps even net negative). But if catastrophic climate change is somewhere in the foreseeable future, an overshoot pathway could in fact push us over the "climate cliff".

Of course, we do not know the likelihood of the future described above. Some have argued strenuously that it is highly unlikely, in terms of a variety of aspects: the science, the economics,

\footnotetext{
${ }^{6}$ See, for example, Wise et al. (2009) and Hertel et al. (2010).

${ }^{7}$ See, for example, Rhodes and Keith (2005); Domenichini et al. (2011); Klein et al. (2011).

${ }^{8}$ Solomon et al. (2009).
} 
public opinion, political will, and so forth. Others say that the science is clear; the issue is one of convincing the public and policymakers that such drastic action is required. If the past is any indication, such convincing will require demonstrable and observable evidence that the "cliff" is near. Regardless of the resolution, there appears to be an inconsistency between overshoot, which is intended to reduce GDP losses, and the belief that an unacceptable "tipping point" is near.

\section{Conclusions}

In our analysis, the efficacy of each policy is measured in terms of the costs of mitigation and its capacity to slow radiative forcing and hence temperature change. We have explored both top down and bottom up policies. In the case of the former, we examined a $2.8 \mathrm{os} \mathrm{W} / \mathrm{m}^{2}$ ("os" denotes that overshoot was allowed) and a $3.7 \mathrm{~W} / \mathrm{m}^{2}$ policy. These scenarios assumed complete "when and where" flexibility and full participation from the outset. Finally, we examine bottom-up policy scenarios, or what might be referred to as "second best" approaches, in which individual regions and countries take on emissions reductions of varying stringency based on domestic goals and ability to pay. The G8m proposal reflects an aggressive plan motivated by discussions of world leaders in recent years, while a fragmented policy is intended to reflect an extension of our current course as defined by recent commitments.

We have demonstrated the potentially significant role of a BECS technology in determining the emissions pathway and costs involved in meeting the most stringent of our targets.. If BECS or other negative emissions options are not to be used, phase out of carbon emissions may be necessary at an unprecedented rate. If BECS is to be a significant part of the mix, the possibility exists for significant overshoot on the way to meeting the target, which changes the nature of the environmental outcome. Regardless of the policy scenario, it is clear that R\&D investments that enhance the available suite of technological options will lead to large reductions in the cost of compliance. At the same time, regardless of the technology scenario, it is clear that neither the G8m nor the Fragmented Policy scenarios are likely to stay below a $2{ }^{\circ} \mathrm{C}$ temperature increase, while the inefficient allocation of mitigation effort will significantly increase the costs of a given climate outcome.

Measuring the economic cost of mitigation is only part of the story, but it is an essential part. Economic cost analysis enables us to assess the feasibility of alternative proposals and to determine which measure and technologies can provide the most value. On the other hand, what a rapid transition might mean for net unemployment and social dissonance is far beyond the scope of this analysis. For tight targets, costs both measured and unmeasured are likely to be high, and accepting them will likely call for a great deal of political will. A universal agreement that such a policy is justified would require an overwhelming belief that catastrophic climate change is imminent. Given public sentiment to date, this will require a major shift in current thinking.

We close by noting that a reduction in emissions is not the sole policy response available. Adaptation is also an option. At which point is adaptation more cost-effective than mitigation? A careful analysis is a prerequisite for identifying where that point might be. Delays in climate system response suggest that adaptation may be the only option for near-term climate change. The issue of what constitutes expensive depends upon society's perception of what is at stake. The greater the apparent threat, the higher will be our willingness to pay to protect current and future generations. Unfortunately, there remains considerable uncertainty regarding the stakes and their likelihood. As noted in the recent report by the National Academy of Sciences "America's Climate Choices", 9 the issue calls for iterative risk management. Our strategy

\footnotetext{
${ }^{9}$ Carnesale et al. (2011).
} 
should be to take action based on the best information available and to be prepared to make midcourse corrections as better information is obtained.

Open Access This article is distributed under the terms of the Creative Commons Attribution License which permits any use, distribution, and reproduction in any medium, provided the original author(s) and the source are credited.

\section{References}

Blanford GJ, Richels RG, Rutherford TF (2009) Feasible climate targets: the roles of economic growth, coalition development, and expectations. Energy Econ 31:S82-S93

Blanford et al (submitted for this volume) Cooperation vs. fragmentation: overview on climate policy scenarios in the EMF27 scenarios. Clim Chang (submitted for this volume)

Carnesale et al (2011) America's climate choices. Committee on America's climate choices. National Research Council. The National Academies Press, Washington, DC. www.nap.edu

Clarke LE, Edmonds JA, Krey V, Richels RG, Rose S, Tavoni M (2009) International climate policy architectures: overview of the EMF 22 international scenarios. Energy Econ 31(2):S64-S81

Domenichini R, Gasparini F, Cotone P, Santos S (2011) Techno-economic evaluation of biomass fired or cofired power plants with post combustion CO2 capture. Energy Procedia 4(2011):1851-1860

Hertel T, Golub A, Jones A, O'Hare M, Plevin R, Kammen D (2010) Effects of U.S. maize ethanol on global land use and greenhouse gas emissions: estimating market-mediated responses. BioScience 60(3):223-231

Klein D, Bauer N, Bodirsky B, Dietrich JP, Popp A (2011) Bio-IGCC with CCS as a long-term mitigation option in a coupled energy-system and land-use model. Energy Procedia 4(2011):2933-2940

Nordhaus W (1979) The efficient use of energy resources. University Press, New Haven

Rhodes JS, Keith DW (2005) Engineering economic analysis of biomass IGCC with carbon capture and storage. Biomass Bioenergy 29(2005):440-450

Solomon S, Plattnerb G-K, Knuttic R, Friedlingstein P (2009) Irreversible climate change due to carbon dioxide emissions. Proc Natl Acad Sci 106:1704-1709

Solomon et al (2011) Climate stabilization targets: Emissions, concentrations, and impacts over decades to millennia. Committee on stabilization targets for atmospheric greenhouse gas concentrations. National Research Council. The National Academies Press, Washington, DC. www.nap.edu

Wise M, Calvin K, Thomson A, Clarke L, Bond-Lamberty B, Sands R, Smith SJ, Janetos A, Edmonds J (2009) Implications of limiting CO2 concentrations for land use and energy. Science 324:1183-1186 